\title{
SOURCING SODIUM HYDROGEN CARBONATE FROM LAKE SALT FOR THE FORMULATION OF BAKING POWDER
}

\author{
A.G. Kassim**, G.F.S. Harrison and E.J. Ekanem* \\ Department of Chemistry, Almadu Bello University, Zaria, Nigeria.
}

\begin{abstract}
Controlled acid conversion of the carbonate in crystallised fractions of lake salt to the bicarbonate was carried out in solution and solid products obtained from the solutions by recrystr!lisation. Frowncts containing up to $88.44 \pm 1.05 \%$ bicarbonate were obtained when hydrochloric acid was used and up to $74.95 \pm 1.39 \%$ when ethanoic acid was used. $A$ baking powder was formulated using the isolated sodium bicarbonate. The baking powder, when in contact with wate; behaved in a similar manner to a commercial baking powder. The formulated baking powiler was also used in baking and the baked products were found to be very similar to those obtained witi the coinmercial buking powder.
\end{abstract}

\section{INTRODUCTION}

Läke sait is a substance obtained on evaporation of certain lakes in arid regions. ${ }^{1}$ It is taken as medicine for various ailments in Northern Nigeria. It is also used as tenderiser in cooking and in driliking water for cattle.?

In Northern Nigeria, the salt is called 'kanwa' in Hausa. However, lake salt is called by various names such as potash, even though some samples may contain little or no potassium, natron and trona implying the presence of $\mathrm{Na}_{2} \mathrm{CO}_{3} \cdot 10 \mathrm{H}_{2} \mathrm{O}$ and $\mathrm{NaHCO}_{3} .2 \mathrm{H}_{2} \mathrm{O}$ respectively. ${ }^{3}$

Different varieties of lake salt are known and are in use locally in Northern Nigeria. The most common ones include 'jar kanwa' (red 'kanwa'), 'farar kanwa' (white 'kanwa'), 'manda', 'ungurnu' and 'mangul'. Different varieties may have different compositions depending upon the type of lake in which they were formed. The major cation present is that of sodium $\left(\mathrm{Na}^{+}\right)$. Potassium is also present in small amounts ${ }^{4.5}$. In addition, some samples may also contain calcium (as $\mathrm{CaCO}_{3}$ ) and magnesium ions and manganese has also been shown to be present in certain samples ${ }^{2,4,5}$. The major anions present include those of carbonate $\left(\mathrm{CO}_{3}^{2-}\right)$ bicarbonate $\left(\mathrm{HCO}_{3}{ }^{-}\right)$, chloride $(\mathrm{Cl})$ and sulphate $\left(\mathrm{SO}_{4}{ }^{2-}\right)^{4,5,6}$.

\footnotetext{
* Author for correspondence

**Present address: Department of Chemistry, Federal College of Education Zaria, Nigeria.
}

Various chemical substances are obtained from lake salt deposits including sodium carbonate, sodium bicarbonate and sodium sulphate. The chief method used is fractional crystallisation as the salts ikave different solubilities. However, for the extraction of sodium bicarbonate, carbon dioxide is first bubbieu through the solution to react with the sodium carbonare to form sodiux bicarbonate which immediately precipitates out as it is less soluble. The reaction can be represented as

$$
\mathrm{CO}_{3}^{2-}+\mathrm{CO}_{2}+\mathrm{H}_{2} \mathrm{O} \cdots 2 \mathrm{HCO}_{3}^{-}
$$

The aim of this work was to optimise a method for concentrating and extracting sodium bicarbonate from lake salt by acid conversion of the carbonate present in it to the bicarbonate and crystallising out. The reaction can be represented as

$$
\mathrm{CO}_{3}^{2-}+\mathrm{H}^{+}-\mathrm{HCO}_{3}
$$

It was desired to use the sodium bicarbonate so extracted in formulating baking powder. The established methods for manufacturing sodium bicarbonate, such as the Solvay process, require the use of complex equipment for the generation of ammonia and carbon dioxide which are used as raw mateials, and also the tall carbonating towers used. The proposed method for obtaining sodium bicarbonate from lake salt by controlled acid conversion of carbonate eliminates the use of such complex equipment and is cheaper since, also, the lake salt used as raw material is readily available. 
The U.S. Department of Agriculture defines baking powder as the leavening agent produced by mixing of an acid-seacting material and sodium bicarbonate with or 'vithout the addition of starch or flour. The permiss ible acid ingredients are tartaric acid or its acid salti, monocalcium phosphate, alum or a combination of them. ${ }^{8}$

\section{EXPERIMENTAL}

\section{Lakesalt samples}

The samples of lakesalt chosen were those which looked relatively clean' to the eye and contained minimum amount of earthy impurities. Samples which had high carbonate/bicarbonate content were preferred.

\section{Alum}

The alum used as the acid ingredient was obtained from the market. It was purified by crystallisation and dried in air.

\section{Starch}

Corn starch was also obtained from the market and washed with wate $r$ and dried in air.

\section{Dilute $\mathrm{HCl}$}

$0.20 \mathrm{M} \mathrm{HCl}$ was obtained by diluting $10.1 \mathrm{M}$

"Analar" grade $\mathrm{HCl}$ and standardised against sodiun carbonate.

\section{Acetic acid}

16.67 $\mathrm{M} \mathrm{CH}_{3} \mathrm{COOH}$ was used. It was standardised using standard $\mathrm{NaOH}$ solution.

\section{Purification and concentration of the lake salt by crystallisation}

$100.0 \mathrm{~g}$ of the sa:nple of lake salt was dissolved in minimum amount of water and filtered. The filtrate was further concentrated by evaporation over a steambath and allowed to cool. Crystallisation was allowed to zontinue overnight. The crystals were then filtered and washed with ethanol and dried in air.

\section{Determination of carbonate-bicarbonate ratio in the crystallized fraction}

$0.30 \mathrm{~g}$ of the cry stallized fraction was dissolved in minimum distill $2 \mathrm{~d}$ water. The solution was titrated with $0.2 \mathrm{M} \mathrm{HCl}$ using phenolphthalein and methyl orange indicators successively in a double end point titration. The percentage of bicarbonate and carbonate in the friction was calculated. Typical average results of triplicate determinations are shown in Table 1 for the first crop of crystals obtained from a selected sample.

Acid conversion of carbonate to bicarbonate in the fractions.

$5.0 \mathrm{~g}$ of the crystallized fraction was dissolved in a minimum amount of water. $2.10 \mathrm{~cm}^{3}$ of $10.10 \mathrm{M}$ $\mathrm{HCl}$ was added very carefully with stirring. The mixture was gently heated to concentrate it and then allowed to cool. Crystals were formed which were filtered out, washed and dried in air before weighing. The results are also shown in Table 1 as averages of three determinations.

Anotler $5.0 \mathrm{~g}$ of the crystallized sample fraction was dissolved in minimum water and reacted with $1.3 \mathrm{~cm}^{3}$ of $16.67 \mathrm{M} \mathrm{CH}_{3} \mathrm{COOH}$. The mixture was treated as previously done with $\mathrm{HCl}$ to obtain crystals which were dried and weighed.

The volume of acid used in both cases contains the equivalent amount of the acid required to convert the sodium carbonate present in $5.0 \mathrm{~g}$ of the fraction to the bicarbonate according to their stoichiometric equations.

In each case the bicarbonate to carbonate ratio of the product was determined by titrating $0.20 \mathrm{~g}$ of each product against $0.20 \mathrm{M} \mathrm{HCl}$ using phen ophthalein and methyl orange successively as niduis ours. The results are also shown in Table 1 as averages of three determinations.

Table 1: Percentage of $\mathrm{CO}_{3}{ }^{-}$and $\mathrm{HCO}_{3}{ }^{-}$in fractions

\begin{tabular}{lcc}
\hline & \multicolumn{2}{c}{$\%$ in sample } \\
\cline { 2 - 3 } & $\mathrm{CO}_{3}^{2-}$ & $\mathrm{HCO}_{3}$ \\
\hline First crystallized fraction & $44.77 \pm 0.37$ & $35.10 \pm 0.44$ \\
\hline $\mathrm{HCl}$ treated fraction & $5.30 \pm 0.80$ & $88.44 \pm 1.05$ \\
$\begin{array}{l}\mathrm{CH}_{3} \mathrm{COOH} \text { treated } \\
\text { fraction }\end{array}$ & $14.13 \pm 1.20$ & $74.94 \pm 1.39$ \\
\hline
\end{tabular}

Analysis of commercial baking powder

A brand (Royal Active) of baking powder was analysed for the relative amounts of the acid ingredient and starch used. The acid ingredient was determined as aluminium by the gravimetric method? It was then calculated as the amount of alum present. The amount of sodium bicarbonate was found by difference. The results are shown in Table 2 as averages of three determinations.

Formulation of baking powder

Using the sodiun bicarbonate obtained from lake 
salt as leavening agent, a baking powder was formulated using alum as acid ingredient and starch as filler. The formulation was done to simulate the composition of the commercial brand as slown in Table 2. The constituents were ground together and mixed thoroughly.

Evaluation and properties of the formulated baking powder

A little of the formulated baking powder was put in a beaker and a small amount of water added. The experiment was also performed with the commercial baking powder. The formulated and commer-

Table 2: Composition of baking powder sample

\begin{tabular}{lc}
\hline Constituent & Percentage \\
\hline Sodium bicarbonate & 30.00 \\
Alum & 37.60 \\
Starch & 32.40 \\
\hline
\end{tabular}

cial baking powders were used in baking and the products compared by observing various parameters such as volume gain, physical appearance and taste.

\section{RESULTS AND DISCUSSION}

\section{Extraction of bicarbonate}

The percentage of carbonate in the fraction was approximated to $45 \%$ when calculating the amount of acid required to convert the carbonate present in the fraction to the bicarbonate. Concentrated acid was used in order to minimize the volume of solution applied for crystallisation. Bicarbonate level was enhanced 2.52 -fold and 2.14-fold by $\mathrm{HCl}$ and $\mathrm{CH}_{3} \mathrm{COOH}$ respectively.

\section{Properties of the formulated baking powder}

Both the commercial and formulated baking powders gave very similar gentle frothing when in contact with water. The volume gain for the baked product obtained by using the formulated baking powder was about $35 \%$ while that using commercial powder was about $36 \%$. Both products had very similar brownish appearance and they all tasted similar. The products also retained their shapes and sizes after storage for three days.

\section{CONCLUSION}

The reaction of the carbonate present in lake salt with acid can be carefully controlled to permit the concentration and subsequent isolation of a solid product very rich in bicarbonate. This product could be used for making baking powders and baked product which could be very similar to those obtained with commercial baking powder.

\section{REFERENCES}

1. Bateman, A.M., The Formation of Mineral Deposits, John Willey and Sons, New York, 1951.

2. Buchanan, K.M. and Pugh, J.C., Land and People in Nigeria, 8th imp., University of London, 1971.

3. Palache, C., Berman, H. and Frondel, C., Dana's System of Minerology, 7th ed., Vol.II, John Willey and Sons, London, 1951.

4. Ekanem, E.J. and Harrison, G.F.S., Nig. Jour. Chem. Res., 1997, $2,33$.

5. Ekanem E.J., M.Sc. Thesis, Ahmadu Bello University, 1977.

6. Ako, P.A.E. and Harrison, G.F.S., Nig. Jour. Technol. Res., 1990, 2, 39.

7. Van Thoor, T.J.W., ed., Materials and Technology, Vol. 1, Inorganic Chemicals, London, 1968.

8. Peckham, G.C. and Freeland-Graves, J.H., Foundation of Food Preparation, 4th ed., Macmillan, London, 1979.

9. Tikhonov, V.N., Analytical Chemistry of Aluminium, John Willey and Sons, Israel, 1971.

10. Egan, H., Kirk, R.S. and Sawyer, R., Chemial Analysis of Foods, 8th ed. Churchill Livingtone, London, 1981.

accepted 8/3/99

received 17/9/98 